\title{
PLANTAS MELÍFERAS DE RORAIMA - PARTE II
}

\author{
Sílvio José Reis da Silva
}

Maria Agripina Pereira Rebouças ${ }^{1}$

RESUMO:. Das 31 plantas observadas, as que indicaram ter um potencial para produção de mel por Apis mellifera L foram: Acacia lorentensis Macbr. (Miguel Corrêa), Mimosa pudica L., Mimosa sp., Melochia hirsuta Cav. (vassoura), Waltheria americana L., Sida sp., Vochysia guianensis Aubl (guaruba), Bauhinia ungulata L. (mororó) e Peltogyne sp., Protium spruceanum Engl. (breu), Sesamum indicum DC (gergelim bravo). Em sedimentos das amostras de mel, os tipos polínicos encontrados foram: Mimosa sp., Acacia sp., Bauhinia ungulata L., Protium sp e Vochysia guianensis Aubl. As amostras com pólen de Protium sp. e Vochysia guianensis apresentaram sabor amargo.

Palavras - chave: Abelhas, Apis mellifera, Plantas Melíferas.

ABSTRACT: Of 31 plants observed, those with indications of potential for production of honey by Apis mellifera L were: Acacia lorentesis Macbr., Mimosa pudica L., Mimosa sp., Melochia hirsuta Cav., Waltheria americana L., Sida sp., Vochysia guianensis Aubl., Bauhinia ungulata L. e Peltogyne sp., Protium spruceanum Engl., Sesamum indicum DC. In initial analyse of honey sample we find as mean pollen type: Mimosa sp., Acacia sp., Bauhinia ungulata L., Protium sp. e Vochysia guianensis Aubl. The samples of honey that contained pollen of Protium sp. and Vochysia guianensis had a bitter taste.

Key Words: Bees, Apis mellifera, Bee Plants, Roraima state.

\footnotetext{
1 Pesquisadores do Núcleo de Zoologia do MIRR

Bol. do Mus. Integrado de Roraima, Boa Vista, 4(único): 31-38, 1998
} 


\section{INTRODUÇÃO}

A flora apícola brasileira é muito diversificada, produzindo diferentes tipos de méis com diversos sabores. A variação é tal que apiários situados a poucos quilômetros um do outro podem produzir méis bastante diferentes (WIESE, 1974).

Poucos são os trabalhos realizados sobre as fontes de alimento para Apis mellifera L. na Amazônia. CARREIRA et al. (1986) analisou o pólen de sedimento de méis provenientes de Belém, Benfica, São Francisco do Pará e Tomé Açu. BARTH (1987) observou abelhas coletando alimento em flores de vegetação de canga alagada e seca nas minas da Serra de Carajás, Pará. Em Roraima, SILVA (1990), através de observações da atividade de coleta de alimento, listou 19 plantas utilizadas por $A$. mellifera para obtenção de pólen e néctar. MARQUES - SoUZA et al. (1993) listou 126 tipos de pólen encontrados em corbículas de Apis mellifera L. em Ji-Paraná, Rondônia.

A nível nacional, podemos destacar o trabalho de BARTH (1989), onde são descritos os principais tipos polínicos encontrados em méis de diferentes regiões do Brasil; destacamos também o trabalho coordenado por PIRANI \& CORTOPASSI-LAURINO (1993), onde foi dada uma descrição detalhada das principais plantas melíferas encontradas em são Paulo.

Este estudo teve por objetivo identificar as espécies botânicas utilizadas como alimento por A. mellifera, através de observações das atividades de coleta nas flores, complementados com análises polínicas dos sedimentos de mel obtidos de sete apiários.

\section{MATERIAL E MÉTODOS}

Descrição da região do estudo

Roraima é o estado mais ao norte do Brasil, parte de seu território $\left(44.000 \mathrm{~km}^{2}\right)$ está coberto por savanas; as florestas cobrem $170.000 \mathrm{Km}^{2}$ e as áreas restantes possuem vegetação de transição (FREITAS, 1996).

o clima predominante, nas áreas de estudo, é o tropical, com nítida estação seca que vai de setembro a março (Awi na classificação de Köppen, (IBGE, 1981)). As médias anuais de temperatura, umidade relativa e do índice de precipitação para

Bol. do Mus. Integrado de Roraima, Boa Vista, 4(único): 31-38, 1998 
Boa Vista são respectivamente, $27,4^{\circ} \mathrm{C}, \quad 76 \%$ e $1502,91 \mathrm{~mm}$ (EMBRAPA-UEPAT, 1982).

As observações foram realizadas nas localidades de contão; Taiano, Fazenda SB; Tabalascada, Boa Vista, Serra Grande e Tamandaré, nos anos de 1991 e 1995 .

Procedimentos de campo e laboratório

De cada planta visitada por A. mellifera, foram montadas duas exsicatas de ramos com flores. O material coletado foi determinado através do comportamento das abelhas campeiras nas flores, tomando por base as considerações de MICHENER et al. (1978) e ROUBIK (1989).

O período de floração foi considerado como sendo aquele em que o maior número de indivíduos da espécie estava com flores.

Três botões florais de cada espécie botânica visitada foram destacados para a preparação de lâminas de pólen, através dos seguintes procedimentos: 1/ Maceração dos botões florais em álcool 70\%; 2/ Filtragem do material em tela fina; 3/ Decantação do material; 4/ Após a decantação o álcool é desprezado restando o sedimento com o pólen; 5/ Uma pequena fração do sedimento foi espalhada em lâmina de microscópio com gelatina glicerinada; 6/ Colocação de uma lamínula; 7/ Lutagem com parafina; 8/ Colocação de etiquetas de identificação da amostra.

Analisamos 56 amostras de mel. Foram preparadas lâminas do sedimento pelo método de BARTH (1989), para análise, ao microscópio ótico, do pólen contido em seus sedimentos e posterior comparação com as lâminas de pólen montadas das plantas melíferas coletadas.

\section{RESULTADOS E DISCUSSÃO}

Na Tabela 1 estão relacionadas 33 espécies (18 famílias e 27 gêneros) coletadas durante as observações de campo. A maioria destas plantas é reconhecida como apícola em outros estados do Brasil (KERR et al., 1987; BRANDÃO, 1985; CAMARGO, 1972; BARTH, 1989).

Tabela 1: Relação das famílias e espécies de plantas observadas e suas características Api-botânicas, nas

Bol. do Mus. Integrado de Roraima, Boa Vista, 4(único): 31-38, 1998 
localidades estudadas, 1991 - 1996.

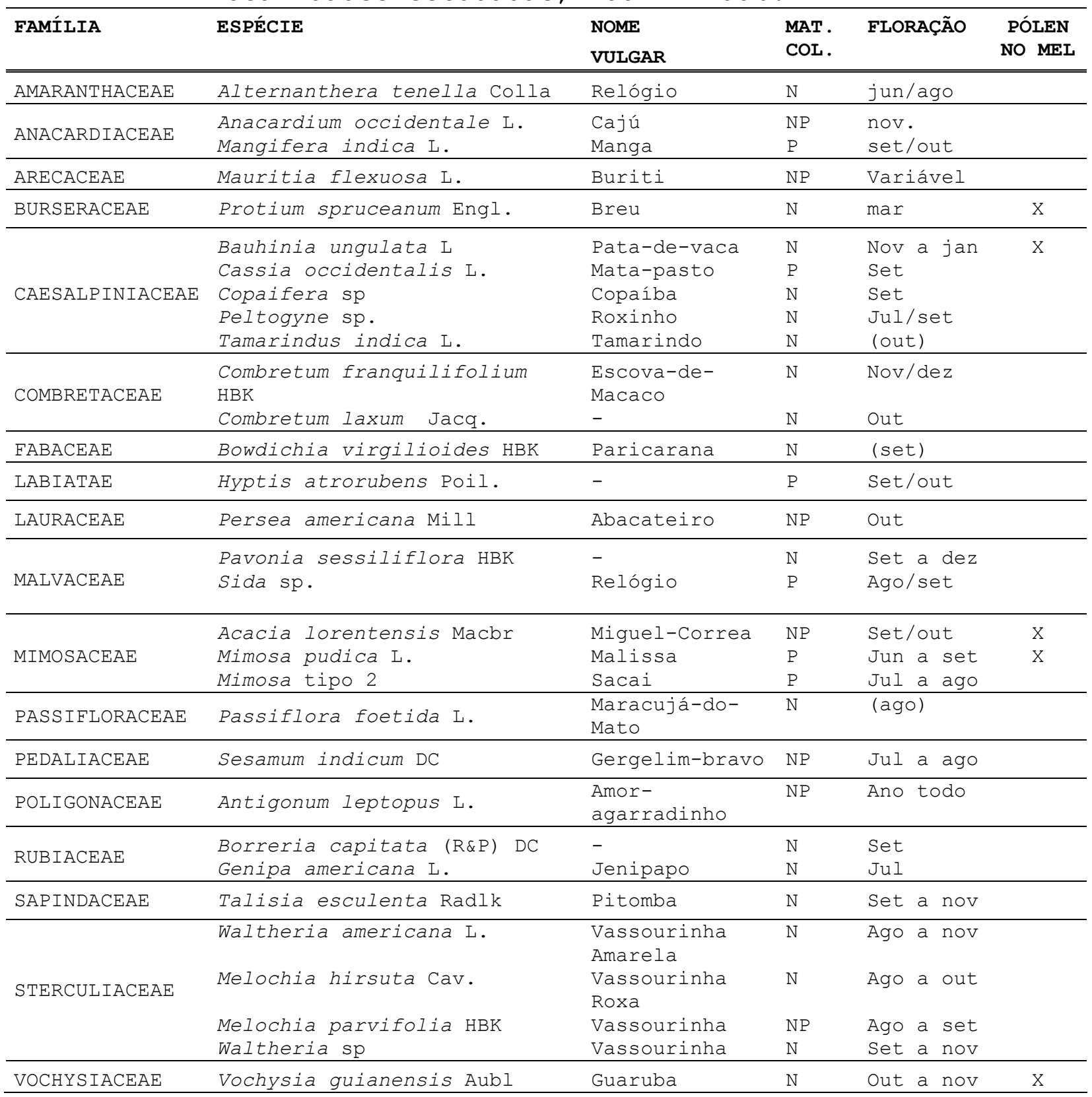

${ }^{*} \mathrm{~N}=$ néctar $\mathrm{P}=$ pólen $\mathrm{NP}=$ néctar e pólen.

Embora Anacardium occidentale L., Bauhinia ungulata L. e Combretum franquilifolium H. B. K. tenham baixa visitação, o potencial apícola destas espécies é muito alto. A espécie

Bol. do Mus. Integrado de Roraima, Boa Vista, 4(único) : 31-38, 1998 
A. occidentale não pelo néctar de suas flores, mas sim pelo suco de seus frutos (pedúnculos) que ocorrem em uma época de escassez de alimento para as abelhas (janeiro a março), sendo intensamente procurados, chegando as abelhas a picarem quem lhes tente tirar o alimento. KERR et al. (1987) já tinham observado este fato no Maranhão. B. ungulata apresenta poucas flores maduras por indivíduo ocorrendo porém, uma sucessão constante, de tal forma que havendo umidade no solo a floração pode se estender por três meses ou mais, e cada flor exsuda uma grande quantidade de néctar. C. franquilifolium produz uma inflorescência formada por dezenas de flores carregadas de néctar, entretanto, o acesso é dificultado pela trama de estames.

As malváceas são normalmente fornecedoras de pólen, em nosso estudo. Sida spp. foi procurada para pólen. BRANDÃo (1985) observou em $S$. cordifolia L. e S. Iinifolia Cav., a procura para pólen em Minas Gerais. CASTRO (1994), CAMARGO (1972) e MARQUES - SOUZA et al (1993) também citam $S$. cordifolia como fonte de pólen.

Mangifera indica L. é uma frutífera muito cultivada em Roraima. Pela sua ampla distribuíção era de se esperar uma grande produção de mel oriundo do néctar desta espécie. Neste estudo observamos que suas flores não são muito procuradas, e quando o são, é apenas pelo pólen. MALERBO \& NOGUEIRA - COUTO (1992) observaram que A. mellifera coleta néctar de $M$. indica e SILVA (1992) cita que esta espécie é uma importante planta apícola não informando qual a aptidão se pólen ou néctar. Estas discordâncias podem advir do fato de que uma mesma espécie pode ser procurada intensamente em um local, enquanto que em outro a procura pode ser fraca ou até nula, pois os recursos florais serão selecionados através da relação custo/benefício; quanto mais favorável for esta relação maior será a procura (ROUBIK, 1989).

A grande maioria das plantas estudadas floresceu de julho a dezembro, isto, provavelmente, se deve ao fato de que as chuvas se concentram entre os meses de maio a agosto, geralmente com mais de 50 \% da precipitação anual (Fig. 1). A partir de setembro as chuvas são poucas e esparsas e a insolação é alta; - solo porém, encontra-se com o lençol freático próximo a superfície por alguns meses, além da época chuvosa (IBGE, 1981). Deste modo, as plantas terão uma boa fonte de água no solo e poderão secretar grande quantidade de néctar, que será

Bol. do Mus. Intearado de Roraima. Boa Vista. 4 (ínico): 31-38. 1998 
concentrado por evaporação, devido a alta temperatura e a umidade mais baixa no período da estiagem.

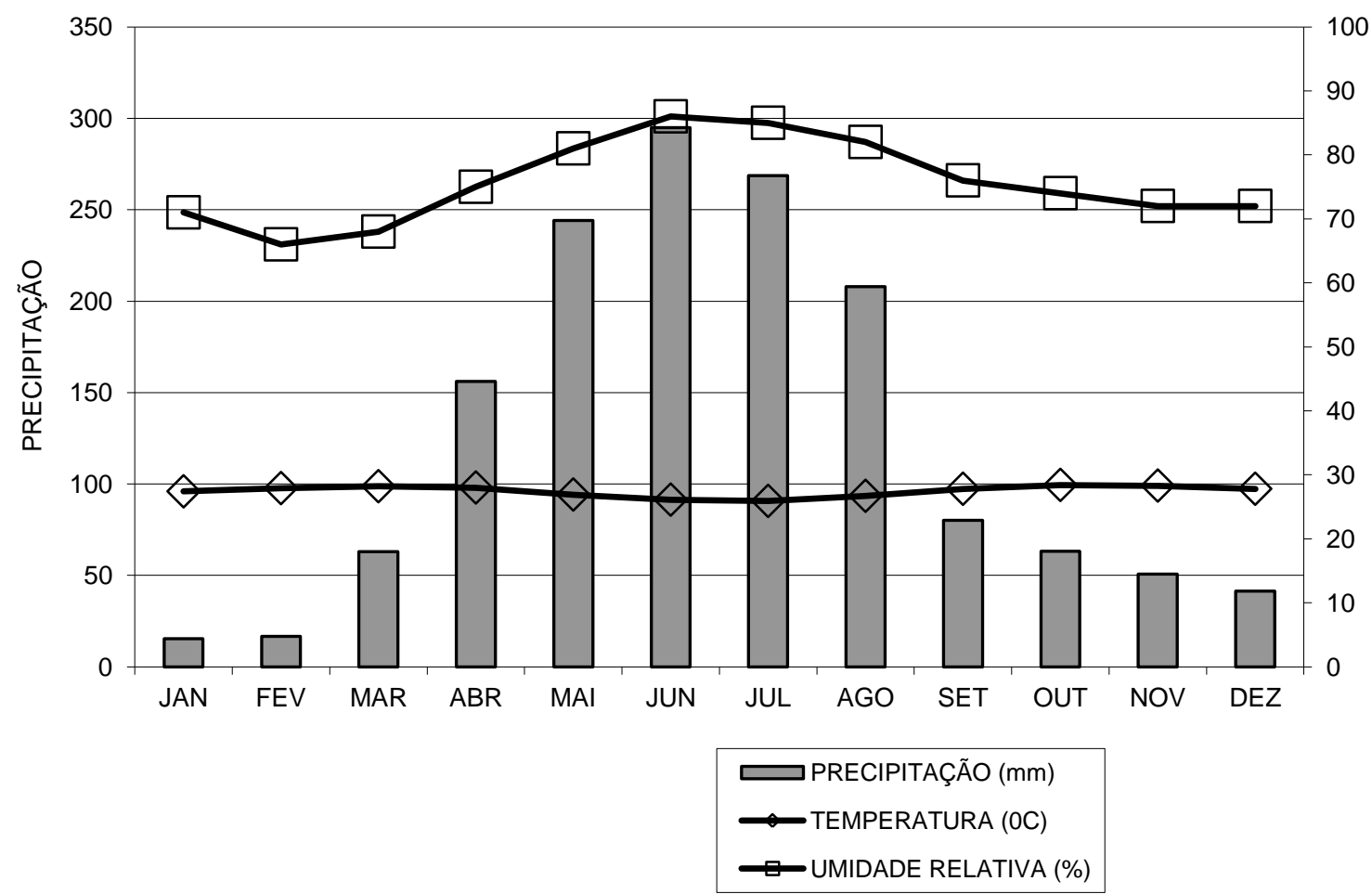

Fig. 1. Médias mensais de temperatura, umidade relativa e precipitação para Boa Vista de 1970 a 1982 (Fonte: INEMET - RR IN EMBRAPA-UEPAT, 1982

Das 31 plantas melíferas coletadas, encontramos como tipos polínicos nos sedimentos de mel: Mimosa sp., Acacia sp., Bauhinia ungulata L., Protium sp. e Vochysia guianensis Aubl.

As amostras de mel que continham pólen de Protium sp. e Vochysia guianensis, apresentaram sabor amargo sugerindo a provável origem do mel amargo em Roraima, uma vez que o gênero Protium sp. possui várias espécies amplamente distribuídas na Amazônia (RODRIGUES, 1989) e V. guianensis é considerada muito comum nas regiões de origem deste tipo de mel. MARQUES - SOUZA (1993) relaciona Protium sp. e Vochysia sp como plantas visitadas por A. mellifera, em Ji-Paraná, RO. Mel amargo não é de todo incomum. BARTH (1990)menciona que o mel produzido de Mimosa bracatinga é tão amargo que só é usado para remédio, enquanto o mel de outra espécie do mesmo gênero ( $M$.

Bol. do Mus. Integrado de Roraima, Boa Vista, 4 (único): 31-38, 1998 
caesalpiniaefolia) é doce e muito apreciado. Além das $A$. Mellifera outras espécies de abelhas também são citadas como visitantes florais de Protium sp. (ABSY \& KERR, 1977; ABSY et al., 1984; BARTH, 1989).

\section{BIBLIOGRAFIA}

ABSY, M. L. \& KERR, W. E., 1977. Algumas plantas visitadas para obtenção de pólen por operárias de Melipona seminigra merrilae em Manaus. Acta Amazonica, 7 (3): 309-315.

ABSY, M. L.; CAMARGO, J. M. F.; KERR, W. E. \&MIRANDA, I. P. A. 1984. Espécie de plantas visitadas por Meliponinae (Hymenoptera, Apoidea), para coleta de pólen na região do médio Amazonas. Rev. Brasil. de Biologia, 44 (2) : 227-237.

BARTH, O. M. 1987. Importância apícola dos campos naturais e rupestres da Serra Norte de Carajás. Bol. Mus. Par. Emílio Goeld, série Bot., 3 (1): 21-28

BARTH, O. M. 1989. O pólen no mel brasileiro. Instituto Oswaldo Cruz. Publicação Avulsa. Rio de Janeiro, RJ. 151p.

BARTH, O. M. 1990. Pollen in monofloral honeys from Brazil. Journal of Apicultural Research 29 (2): 89-94.

BRANDÃO, M. 1985. Comunidades antrópicas como fonte de néctar e pólen. Belo Horizonte, EPAMIG. 32p (Documento, 25).

CAMARGo, J. M. F. de, 1972. Manual de Apicultura. São Paulo, Agronômica Ceres. 252p.

CARREIRA, L. M. M.; JARDIM, M. A. G.; MOURA, C. O.; PONTES, M. A. O. \& MARQUES, R. V., 1986. Análise polínica nos méis de alguns municípios do estado do Pará - I Simpósio do Trópico Úmido. EMBRAPA/CPATU, Belém, PA, vol. II, pp. 79-84

CASTRO, M. S. C. 1994. Flora apícola da Bahia. Anais do X Congresso Brasileiro de Apicultura. Pousada do Rio Quente, Go. Brasil. pp. 147.

EMBRAPA - UEPAT. 1982. Relatório Técnico Anual da Unidade de Execução de Pesquisa de Âmbito Territorial de Boa Vista. $212 \mathrm{p}$.

FREITAS, A. 1996. Geografia e História de Roraima. Manaus, Grafima. $154 \mathrm{p}$.

Bol. do Mus. Intearado de Roraima. Boa Vista. 4 (ínico): 31-38. 1998 
IBGE - Instituto de Geografia e Estatística. 1981. Atlas de Roraima. Rio de Janeiro.

KERR, W. E., ABSY, M. L. \& MARQUES - SOUZA, A. C. M. 1987. Espécies nectaríferas e poliníferas utilizadas pela abelha Melipona compressipes fasciculata (Meliponinae, Apidae), no Maranhão. Acta Amazonica. 16/17 (único): 145-156.

MALERBO, D. T. S. \& NOGUEIRA - COUTO, R. H. 1992. Flora apícola e desenvolvimento de colmeias de Apis mellifera L. em área agrícola na região de Jaboticabal (SP). Científica, São Paulo. 20 (2): 351-358.

MARQUES - SOUZA, A. C.; ABSY, M. L. ; CONDÉ, P. A. A. \& COELHO, H. A. 1993. Dados da obtenção de pólen por duas operárias de Apis mellifera no município de Ji-Paraná (RO), Brasil. Acta Amazonica, 23 (1): 56-76.

MICHENER, D. C., WINSTON, M. L. \& JANDER, R. 1978. Pollen manipulaition and related activities and structure and bees of the family Apidae. Univ. Kan. Sci. Bull. 51: 575-601.

PIRANI, M. \& CORTOPASSI - LAURINO, M., 1993. Flores e abelhas em São Paulo. São Paulo, EDUSP/FAPESP. 192p

Rodrigues, R. M. 1989. A Flora da Amazônia. Belém, CEJUP. 462p.

ROUBIK, D. W. 1989. Ecology and natural history of tropical bees. Cambridge, Cambridge University Press. 514p.

SILVA, F. J. M. da. 1992. Levantamento das espécies apícolas do brejo paraibano. II Flora apícola do apiário do Departamento de Zootecnia (DZ) do Centro de Ciências Agrárias (CCA) da Universidade Federal da Paraíba (UFPB). Resumos do IX Congresso Brasileiro de Apicultura. Candelária, RS. pp 197.

SILVA, S. J. R. da. 1990. Plantas melíferas de Roraima. I. Bol. Do Mus. Integrado de Roraima, 1 (1):12-16 (out/nov/dez)

WIESE, H. 1974. Nova Apicultura. Porto Alegre, Agropecuária. $485 \mathrm{p}$.

Recebido em: 07.04 .97

Aceito em: 08.05 .97

Bol. do Mus. Integrado de Roraima, Boa Vista, 4 (único): 31-38, 1998 